\title{
Oral environment and cancer
}

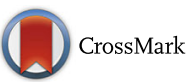

\author{
Yasusei Kudo ${ }^{1 *}$, Hidesuke Tada ${ }^{1,3}$, Natsumi Fujiwara², Yoshiko Tada ${ }^{3}$, Takaaki Tsunematsu', Yoichiro Miyake ${ }^{4}$ \\ and Naozumi Ishimaru'
}

\begin{abstract}
Cancer is now the leading cause of death in Japan. A rapid increase in cancer mortality is expected as Japan is facing a super-aged society. Many causes of cancer are known to be closely linked to life style factors, such as smoking, drinking, and diet. The oral environment is known to be involved in the pathogenesis and development of various diseases such as bronchitis, pneumonia, diabetes, heart disease, and dementia. Because the oral cavity acts as the bodily entrance for air and food, it is constantly exposed to foreign substances, including bacteria and viruses. A large number of bacteria are endemic to the oral cavity, and indigenous oral flora act to prevent the settlement of foreign bacteria. The oral environment is influenced by local factors, including dental plaque, tartar, teeth alignment, occlusion, an incompatible prosthesis, and bad lifestyle habits, and systemic factors, including smoking, consumption of alcohol, irregular lifestyle and eating habits, obesity, stress, hormones, and heredity. It has recently been revealed that the oral environment is associated with cancer. In particular, commensal bacteria in the oral cavity are involved in the development of cancer. Moreover, Candida, human papilloma virus and Epstein-Barr virus as well as commensal bacteria have been reported to be associated with the pathogenesis of cancer. In this review, we introduce recent findings of the correlation between the oral environment and cancer.
\end{abstract}

Keywords: Cancer, Oral environment, Bacteria, Candida, Human papilloma virus, Epstein-Barr virus

\section{Background}

During 2012, approximately 14.1 million new cases of human cancer were reported globally [1]. In Japan, the estimated number of cancer deaths during 2014 was approximately 367,000 [2]. Regarding the age-specific causes of death, during 2013, cancer was the leading cause of death among 40-89 years in Japan [2]. Tobacco use accounts for approximately $22 \%$ of cancer deaths [3], followed by obesity, a poor diet, lack of physical activity, and consumption of alcohol, which collectively account for $10 \%$ of cancer deaths $[3,4]$. Other factors include infections, exposure to ionizing radiation, and environmental pollutants [5]. Thus, various causes of cancer are known to be closely involved in lifestyle choices, such as smoking, drinking, and diet.

The human body is inhabited by over 100 trillion microbial cells living in symbiosis with the host. Many bacteria are endemic to the oral cavity. More than 700 bacterial species inhabit the oral cavity, including at least

\footnotetext{
* Correspondence: yasusei@tokushima-u.ac.jp

${ }^{1}$ Department of Oral Molecular Pathology, Institute of Biomedical Sciences,

Tokushima University Graduate School, Tokushima, Japan

Full list of author information is available at the end of the article
}

11 bacterial phyla and 70 genera. Individuals that practice oral hygiene have 1,000-100,000 bacteria living on each tooth surface, whereas those who do not regularly practice dental hygiene can have between 100 million and 1 billion bacteria on each tooth surface [6]. Although some bacteria of the oral cavity are harmful and can cause serious disease, many of the oral bacteria are in fact beneficial in preventing diseases. Thus, the oral cavity is inhabited by complex multispecies bacterial communities that usually exist in a balanced immunoinflammatory state with the host [7]. It is now established that many chronic inflammatory conditions are caused by an imbalance between host-microbiota interactions, resulting in a dysbiotic community, deregulated immune responses, and eventually disease outcomes. Oral commensal bacteria play a critical role in the development of oral diseases, including periodontal disease and tooth loss, and maintenance of a normal oral physiological environment $[8,9]$. In addition, oral commensal bacteria are involved in the pathogenesis of cancer [10]. Thus, the oral environment including oral commensal bacteria is known to be involved in the pathogenesis and development of various diseases, such as bronchitis and 
pneumonia, diabetes, heart disease, and dementia. The oral environment is influenced by local factors, including dental plaque, tartar, teeth alignment, occlusion, an incompatible prosthesis, and bad lifestyle habits, and systemic factors, including smoking, consumption of alcohol, an irregular lifestyle, eating habits, obesity, stress, hormones, and heredity factors (Fig. 1). Majority of the causes of cancer are thought to be related to tobacco use and heavy alcohol consumption. In the oral environment, poor oral hygiene and viral and Candida infections can be risk factors for cancer.

\section{Oral bacteria and cancer}

The link between oral infections and adverse systemic conditions has attracted a great deal of attention in the dental and medical fields. A major consequence of the systemic spread of oral commensals and pathogens to distant body sites has been the disruption of immune surveillance and homeostasis, resulting in the promotion or acceleration of pathogenic processes. Oral bacteria are involved in systemic infections and inflammation such as cardiovascular disease, adverse pregnancy outcomes, rheumatoid arthritis, aspiration pneumonia, inflammatory bowel disease, organ inflammations, and cancer (Fig. 1). Cumulative studies have revealed that oral bacteria are involved in the initiation or progression of certain cancers. Chronic or dysregulated inflammation contributes to tumor development, partly through the modulation of the tumor microenvironment [11]. Epidemiological studies have shown that the risk of cancer is increased in people with periodontal disease or tooth loss caused by oral bacteria [12]. Oral diseases, including periodontitis, have been related to the risk of oral and gastrointestinal cancers, such as oral, esophageal, gastric and pancreatic cancers $[13,14]$. Although the underlying mechanism for the associations between oral health status and cancers are not completely understood, it has been reported that Fusobacterium nucleatum and Porphyromonas gingivalis are involved in cancer development.

F. nucleatum, an anaerobic Gram-negative oral commensal, is associated with periodontitis, adverse pregnancy outcomes, cardiovascular disease, rheumatoid arthritis, inflammatory bowel disease, and colon cancer [15]. This bacterial species is a key component of periodontal plaque because of its abundance and ability to coaggregate with other species in the oral cavity $[16,17]$. Elevated $F$. nucleatum levels were significantly detected in people with colon cancers compared with that in people with normal colon tissue $[18,19]$. The bacteria genera of Fusobacterium, Porphyromonas, Peptostreptococcus, and Mogibacterium were found to be enriched in the mucosa-adherent microbiota of people with colon cancer [20]. Moreover, the overabundance of Fusobacterium in people with colon cancer was positively associated with lymph node metastasis [18]. In cases of colon cancer, a positive correlation between mRNA levels for several local cytokines and Fusobacterium species has been observed [21]. Although the mechanism by which F. nucleatum might contribute to the pathogenesis of such a diverse clinical spectrum is unknown, recent studies have demonstrated the mechanisms of F. nucleatum in the involvement of colon cancer as follows: i) $F$. nucleatum induces oncogenic and inflammatory responses to stimulate growth of colon cancer cells through FadA adhesin via binding with E-cadherin and ensuing activation of $ß$-catenin signaling [22], ii) $F$. nucleatum generate a proinflammatory microenvironment for the progression of colon cancer through the recruitment of tumor-infiltrating immune cells [23], and

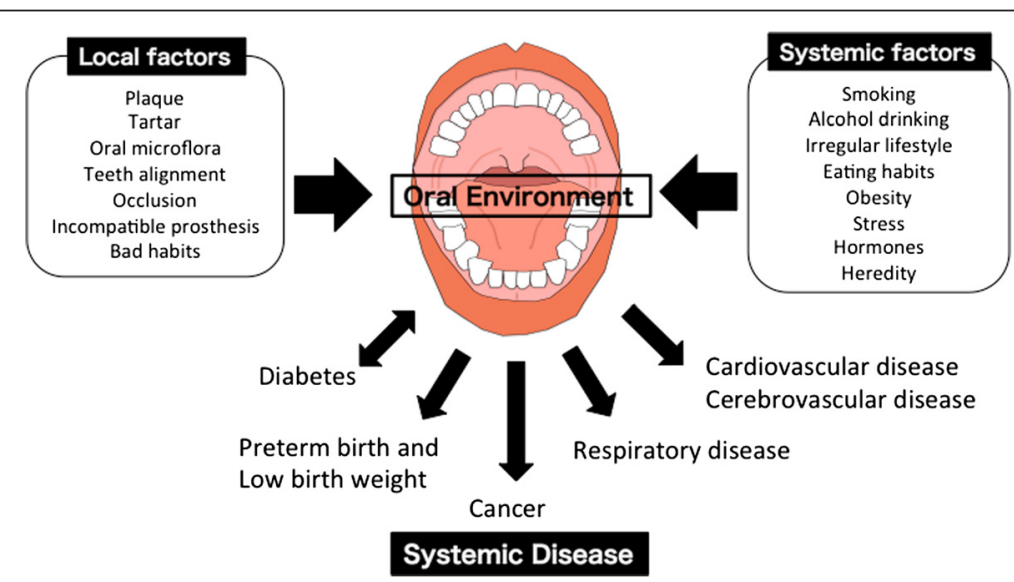

Fig. 1 Influence of Oral Environment on Systemic Disease. The oral environment is influenced by local factors, including dental plaque, tartar, teeth alignment, occlusion, an incompatible prosthesis, and bad lifestyle habits, and systemic factors, including smoking, consumption of alcohol, an irregular lifestyle, eating habits, obesity, stress, hormones, and heredity factors. The oral environment is involved in systematic diseases, such as diabetes, preterm birth and low birth weight, cancer, respiratory disease, cardiovascular disease and cerebrovascular disease 
iii) F. nucleatum interferes with the host immunity by engaging its bacterial protein Fap2 with the inhibitory immunoreceptor TIGIT on NK and T cells [24] (Fig. 2).

Accumulated evidence has shown strong correlations between a number of chronic periodontal bacteria containing Prevotella, Porphyromonas and Streptococcus spp. and orodigestive cancer, including oral squamous cell carcinoma and pancreatic cancer [25-31]. P. gingivalis have an abundance of virulence factors and can be present in periodontal pockets. $P$. gingivalis has a major disruptive effect on local immune responses in the periodontal area [7]. Moreover, it can survive within the oral epithelial tissues and can evade the host immune response [32-37]. In vitro studies have demonstrated that i) $P$. gingivalis strains can induce the expression of the B7-H1 and B7-DC receptors in oral cancer cells, which might facilitate immune evasion by oral cancers [38] and ii) $P$. gingivalis activates the ERK1/2-Ets1, p38/HSP27, and PAR2/NF-kB pathways to induce proMMP9 expression, after which the proenzyme is activated by gingipains to promote cellular invasion of oral cancer cells [39]. In primary cultures of gingival epithelial cells, $P$. gingivalis is strongly antiapoptotic and can suppress chemically induced apoptosis via activation of the Jak1/Akt/Stat3 signaling pathway [40, 41], suggesting that the antiapoptotic effect of $P$. gingivalis may be involved in carcinogenesis. Thus, both $P$. gingivalis and F. nucleatum are involved in cancer progression via activation of cell signaling and/or facilitating immune evasion. However, the possible link between oral bacterium and cancer development remains to be investigated in molecular detail.

\section{Viral and Candida infection and cancer}

Tobacco and alcohol are considered as major risk factors for cancer; however, viral and candidal infection is increasingly being identified to play significant roles in cancer development [42]. Human papillomaviruses (HPVs) are small, double-stranded DNA viruses that induce hyperproliferative lesions in epithelial tissues [43, 44]. More than 100 types of HPV have been identified. Among them, high-risk HPV types, including HPV type 16 (HPV-16), HPV-18, HPV-31, HPV-33, and $\mathrm{HPV}-42$, induce lesions in the genital tract that can progress to malignancy [44-46]. HPV is the most common sexually transmitted viral infection and is well-known as the causative agent of cervical cancer. HPV infection has also been detected in the oral cavity. A large number of studies have demonstrated a 2-3-fold increase in the prevalence of HPV-driven oropharyngeal squamous cell carcinoma over the last three decades, particularly in North America and northern Europe [47-49]. Moreover, a recent review found that many studies have identified a high proportion of oral cancer with detectable HPV DNA [50]. Although the underlying reasons remain poorly understood, changes in sexual behavior, decreased rates of tonsillectomy performed in the pediatric population since the $70 \mathrm{~s}$, and progress in the diagnostic work-up and HPV testing assays have been proposed as the reasons [51-55]. Considering current trends, it is estimated that high-risk HPVs, such as HPV16 and HPV18, cause premalignant lesions [54, 55]. In the high-risk HPV types, E6 and E7 have been shown to function as oncoproteins [56, 57]. E6 and E7 oncoproteins are the key drivers of tumorigenesis by inactivating the tumor suppressors pRb and p53 [58].

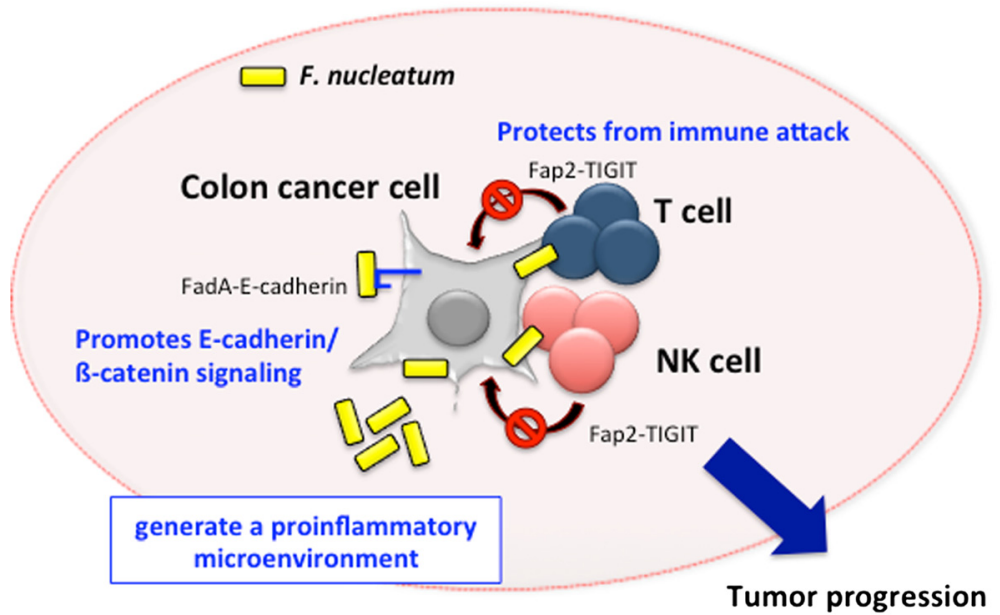

Fig. 2 Involvement of F. nucleatum in colon cancer development. Figure shows the mechanisms of F. nucleatum in the involvement of colon cancer. F. nucleatum promotes E-cadherin/ß-catenin signaling via FadA adhesin and protects from immune attack by engaging its bacterial protein Fap2 with the inhibitory immunoreceptor TIGIT on NK and T cells. Moreover, F. nucleatum generate a proinflammatory microenvironment through the recruitment of tumor-infiltrating immune cells 
Epstein-Barr virus (EBV) causes infectious mononucleosis and oral hairy leukoplakia, and is associated with various types of lymphoid and epithelial malignancies. During 1964, Epstein et al. determined the causative agent of Burkitt's lymphoma to be a previously unknown member of the herpes family of viruses, later termed as EBV [59]. Burkitt lymphoma can be classified into three forms, which differ in geographic distribution and EBV association: endemic, sporadic, and HIV associated Burkitt lymphoma. Among them, endemic Burkitt lymphoma is associated with EBV in over 95 \% cases [60]. Endemic Burkitt lymphoma is predominant in the equatorial belt of Africa and other parts of the world where malaria is hyperendemic [60-63]. On the other hand, although controversial, lymphoepithelial carcinoma and nasopharyngeal carcinoma may also be associated with EBV [64-68]. The association between lymphoepithelial carcinoma and EBV appears to differ according to geographic areas, race, and affected organs. In general, the association of lymphoepithelial carcinoma with EBV is strong in the head and neck region, whereas it is relatively weak at other sites. Moreover, the association is strong in East Asia and relatively weak in western countries. To a great extent, EBV-mediated disruption of cell growth checkpoints relies on direct modulation of cytokine receptor signaling mechanisms and alterations in the expression levels of various cytokines [69]. Moreover, EBV is associated with aggressive types of oral tumors, particularly in immunosuppressed patients [70]. Thus, EBV infection of the oral cavity is also associated with certain types of cancer. However, the pathogenesis of these tumors remains unclear.

Oropharyngeal candidiasis is an opportunistic infection primarily caused by Candida albicans, a ubiquitous fungal organism that is part of the normal microflora of the gastrointestinal and reproductive tracts. Candida species can be isolated as a commensal organism from the oral cavity in up to $80 \%$ healthy individuals [71]. Depending on the host defense mechanisms or oral microenvironment, Candida species can transform from a harmless commensal species to pathogenic organisms causing oral mucosal infection [72, 73]. Candida-associated denture stomatitis affects more than $25 \%$ denture wearers [74], and up to $90 \% \mathrm{HIV}^{+}$patients have had at least one episode of oropharyngeal candidiasis [75]. When dealing with a hyperplastic epithelial lesion of the oral mucosa in which presence of C. albicans is demonstrated, it is referred to by many as Candida-associated leukoplakia or others prefer the term "hyperplastic candidiasis." Chronic hyperplastic candidiasis showed a higher rate of malignant transformation on follow-up [76]. Animal studies have shown that Candida can cause epithelial hyperplasia and cellular atypia [77]. Strains of Candida can produce carcinogenic nitrosamine, $\mathrm{N}$ - nitrosobenzylmethylamine [78]. Thus certain strains of Candida play a key role in oncogene formation and initiation of cancer development [77-79]. However, the possible role of Candida in malignant transformation remains still unclear.

\section{Conclusion}

Many of the causes of cancer are known to be closely linked to lifestyle factors, such as smoking, drinking, and diet. The oral environment is associated with the cause of various diseases, including cancer. The oral environment is influenced by various factors, including local and systemic factors. In the current review, in particular, we introduced the involvement of oral bacteria, funguses, and viruses in the development of cancer. During recent years, the role of oral care for the management of general health has been found to be important within the fields of medical and nursing care. Therefore, oral care for the management of the oral environment can be important for prevention of cancer.

\section{Competing interests}

The authors declare that they have no competing interests.

\section{Authors' contributions}

$Y K, H T, N F, Y T$, and $T T$ wrote the manuscript. YM and NI was involved in the critical revision or supervision of the manuscript. All authors read and approved the final manuscript.

\section{Acknowledgements}

The authors thank Dr. Shinji Oikawa and Dr. Hiroyuki Kamiya, Organizers of The Open Symposium of the JEMS in 2015, and the Japanese Environmental Mutagen Society. The authors would like to thank Enago (www.enago.jp) for the English language review.

\section{Author details}

${ }^{1}$ Department of Oral Molecular Pathology, Institute of Biomedical Sciences, Tokushima University Graduate School, Tokushima, Japan. ${ }^{2}$ Department of Oral Healthcare Promotion, Institute of Biomedical Sciences, Tokushima University Graduate School, Tokushima, Japan. ${ }^{3}$ Tada Dental Clinic, Kakogawa, Japan. ${ }^{4}$ Department of Oral Microbiology, Institute of Biomedical Sciences, Tokushima University Graduate School, Tokushima, Japan.

Received: 14 March 2016 Accepted: 19 April 2016

Published online: 01 August 2016

\section{References}

1. World Health Organization. The global and regional burden of cancer. In: Stewart BW, Wild CP, editors. World Cancer Report 2014. IARC Nonserial Publication. Chapter 1.1.

2. Center for Cancer Control and Information Services, National Cancer Canter, Japan: http://ganjoho.jp/reg_stat/statistics/index.html. 2014. Accessed in February 2016.

3. "Cancer Fact sheet No.297". World Health Organization: http://www.who.int/ mediacentre/factsheets/fs297/en/(2014). Accessed in in February 2016.

4. "Obesity and Cancer Risk". National Cancer Institute: http://www.cancer.gov/ about-cancer/causes-prevention/risk/obesity/obesity-fact-sheet\#q3 (2012). Accessed in in February 2016.

5. Anand $P$, Kunnumakkara $A B$, Kunnumakara AB, Sundaram $C$, Harikumar $K B$, Tharakan ST, et al. Cancer is a preventable disease that requires major lifestyle changes. Pharm Res. 2008:25:2097-116.

6. Jane ES, Desrocher J. "Oral ecology." Technology Review (00401692) 100.1 (Jan. 1997): 48. Academic search premier. EBSCO. Provo, UT: Brigham Young University; 2008. 
7. Hajishengallis G, Lamont RJ. Beyond the red complex and into more complexity: The polymicrobial synergy and dysbiosis (PSD) model of periodontal disease etiology. Mol Oral Microbiol. 2012;27:409-19.

8. Abiko Y, Sato T, Mayanagi G, Takahashi N. Profiling of subgingival plaque biofilm microflora from periodontally healthy subjects and from subjects with periodontitis using quantitative real-time PCR. J Periodontal Res. 2010;45:389-95.

9. Preza D, Olsen I, Willumsen T, Boches SK, Cotton SL, Grinde B, et al. Microarray analysis of the microflora of root caries in elderly. Eur J Clin Microbiol Infect Dis. 2009;28:509-17.

10. Meurman J. Oral microbiota and cancer. J Oral Microbiol. 2010;2:1-10.

11. Rakoff-Nahoum S. Why cancer and inflammation? Yale J Biol Med. 2006; 79:123-30.

12. Pihlstrom BL, Michalowicz BS, Johnson NW. Periodontal diseases. Lancet. 2005;366:1809-20

13. Meyer MS, Joshipura K, Giovannucci E, Michaud DS. A review of the relationship between tooth loss, periodontal disease, and cancer. Cancer Causes Control. 2008;19:895-907.

14. Fitzpatrick SG, Katz J. The association between periodontal disease and cancer: a review of the literature. J Dent. 2010;38:83-95.

15. Han YW. Fusobacterium nucleatum: a commensal-turned pathogen. Curr Op Microb. 2015:23:141-7.

16. Kapatral V, Anderson I, Ivanova N, Reznik G, Los T, Lykidis A, et al. Genome sequence and analysis of the oral bacterium Fusobacterium nucleatum strain ATCC 25586. J Bacteriol. 2002;184:2005-18.

17. Signat $B$, Roques $C$, Poulet $P$, Duffaut $D$. Fusobacterium nucleatum in periodontal health and disease. Curr Issues Mol Biol. 2011;13:25-36.

18. Castellarin M, Warren RL, Freeman JD, Dreolini L, Krzywinski M, Strauss J, et al. Fusobacterium nucleatum infection is prevalent in human colorectal carcinoma. Genome Res. 2012;22:299-306.

19. Kostic AD, Gevers D, Pedamallu CS, Michaud M, Duke F, Earl AM, et al. Genomic analysis identifies association of Fusobacterium with colorectal carcinoma. Genome Res. 2012:22:292-8.

20. Chen W, Liu F, Ling Z, Tong $X$, Xiang C. Human intestinal lumen and mucosa-associated microbiota in patients with colorectal cancer. PLoS One. 2012;7:e39743

21. McCoy AN, Araujo-Perez F, Azcarate-Peril A, Yeh JJ, Sandler RS, Keku TO. Fusobacterium is associated with colorectal adenomas. PLoS One. 2013;8:e53653.

22. Rubinstein MR, Wang X, Liu W, Hao Y, Cai G, Han YW. Fusobacterium nucleatum promotes colorectal carcinogenesis by modulating E-Cadherin/ßCatenin signaling via its FadA Adhesin. Cell Host Microbe. 2013;14:195-206.

23. Kostic AD, Chun E, Robertson L, Glickman JN, Gallini CA, Michaud M, et al. Fusobacterium nucleatum potentiates intestinal tumorigenesis and modulates the tumor-immune microenvironment. Cell Host Microbe. 2013;14:207-15.

24. Gur C, Ibrahim Y, Isaacson B, Yamin R, Abed J, Gamliel M, et al. Binding of the Fap2 protein of Fusobacterium nucleatum to human inhibitory receptor TIGIT protects tumors from immune cell attack. Immunity. 2015;42:344-55.

25. Nagy KN, Sonkodi I, Szoke I, Nagy E, Newman HN. The microflora associated with human oral carcinomas. Oral Oncol. 1998;34:304-8.

26. Mager DL, Haffajee AD, Devlin PM, Norris CM, Posner MR, Goodson JM. The salivary microbiota as a diagnostic indicator of oral cancer: a descriptive, non-randomized study of cancer-free and oral squamous cell carcinoma subjects. J Transl Med. 2005;3:27.

27. Ahn J, Segers S, Hayes RB. Periodontal disease, Porphyromonas gingivalis serum antibody levels and orodigestive cancer mortality. Carcinogenesis. 2012;33:1055-8.

28. Ahn J, Chen CY, Hayes RB. Oral microbiome and oral and gastrointestinal cancer risk. Cancer Causes Control. 2012;23:399-404.

29. Katz J, Onate MD, Pauley KM, Bhattacharyya I, Cha S. Presence of Porphyromonas gingivalis in gingival squamous cell carcinoma. Int J Oral Sci. 2011;3:209-15.

30. Michaud DS, Izard J, Wilhelm-Benartzi CS, You DH, Grote VA, Tjønneland A et al. Plasma antibodies to oral bacteria and risk of pancreatic cancer in a large European prospective cohort study. Gut. 2013;62:1764-70.

31. Michaud DS. Role of bacterial infections in pancreatic cancer. Carcinogenesis. 2013;34:2193-7.

32. Yao $L$, Jermanus $C$, Barbetta B, Choi C, Verbeke $P$, Ojcius DM, et al. Porphyromonas gingivalis infection sequesters pro-apoptotic Bad through Akt in primary gingival epithelial cells. Mol Oral Microbiol. 2010;25:89-101.

33. Yilmaz $\mathrm{O}$. The chronicles of Porphyromonas gingivalis: the microbium, the human oral epithelium and their interplay. Microbiology. 2008;154:2897-903.

34. Yilmaz O, Yao L, Maeda K, Rose TM, Lewis EL, Duman M, et al. ATP scavenging by the intracellular pathogen Porphyromonas gingivalis inhibits P2X7-mediated host-cell apoptosis. Cell Microbiol. 2008;10:863-75.
35. Yilmaz O, Sater AA, Yao L, Koutouzis T, Pettengill M, Ojcius DM. ATPdependent activation of an inflammasome in primary gingival epithelial cells infected by Porphyromonas gingivalis. Cell Microbiol. 2010;12:188-98.

36. Singh A, Wyant T, Anaya-Bergman C, Aduse-Opoku J, Brunner J, Laine ML, et al. The capsule of Porphyromonas gingivalis leads to a reduction in the host inflammatory response, evasion of phagocytosis, and increase in virulence. Infect Immun. 2011;79:4533-42.

37. Choi CH, Spooner R, DeGuzman J, Koutouzis T, Ojcius DM, Yilmaz O. Porphyromonas gingivalis-nucleoside-diphosphate-kinase inhibits ATPinduced reactive-oxygen-species via $\mathrm{P} 2 \mathrm{X} 7$ receptor/NADPH-oxidase signaling and contributes to persistence. Cell Microbiol. 2013;15:961-76.

38. Groeger S, Domann E, Gonzales JR, Chakraborty T, Meyle J. B7-H1 and B7DC receptors of oral squamous carcinoma cells are upregulated by Porphyromonas gingivalis. Immunobiology. 2011;216:1302-10.

39. Inaba H, Sugita $H$, Kuboniwa $M$, et al. (2013) Porphyromonas gingivalis promotes invasion of oral squamous cell carcinoma through induction of proMMP9 and its activation. Cell Microbiol. 2013:16:131-45.

40. Mao S, Park Y, Hasegawa Y, Tribble GD, James CE, Handfield M, et al. Intrinsic apoptotic pathways of gingival epithelial cells modulated by Porphyromonas gingivalis. Cell Microbiol. 2007;9:1997-2007.

41. Yilmaz $O$, Jungas $T$, Verbeke $P$, Ojcius DM. Activation of the phosphatidylinositol 3-kinase/Akt pathway contributes to survival of primary epithelial cells infected with the periodontal pathogen Porphyromonas gingivalis. Infect Immun. 2004;72:3743-51.

42. Bouquot NDA. Oral and maxillofacial pathology. 2nd ed. Philadelphia: Saunders Elsevier; 2002. p. 5055-08.

43. Zur Hausen H, De Villiers EM. Human papillomaviruses. Annu Rev Microbiol. 1994:48:427-47.

44. Howley PM. Papillomavirinae: the viruses and their replication. In: Fields BN, Knipe DM, Howley PM, editors. Fundamental virology. Philadelphia: Lippincott-Raven; 1996. p. 947-78.

45. Laimins LA. The biology of human papillomaviruses: from warts to cancer. Infect Agents Dis. 1993;2:74-86.

46. Zur Hausen H. Papillomaviruses causing cancer: evasion from host-cell control in early events in carcinogenesis. J Natl Cancer Inst. 2000;92:690-8.

47. Chaturvedi AK, Engels EA, Pfeiffer RM, Hernandez BY, Xiao W, Kim E, et al. Human papillomavirus and rising oropharyngeal cancer incidence in the United States. J Clin Oncol. 2011:29:4294-301.

48. Chenevert J, Chiosea S. Incidence of human papillomavirus in oropharyngeal squamous cell carcinomas: now and 50 years ago. Hum Pathol. 2012;43:17-22

49. Garnaes E, Kiss K, Andersen L, Therkildsen MH, Franzmann MB, FiltenborgBarnkob B, et al. A high and increasing HPV prevalence in tonsillar cancers in Eastern Denmark, 2000-2010: the largest registry-based study to date. Int J Cancer. 2015:136:2196-203.

50. Mirghani H, Amen F, Moreau F, Lacau SGJ. Do high-risk human papillomaviruses cause oral cavity squamous cell carcinoma? Oral Oncol. 2015;51:229-36

51. D'Souza G, Agrawal Y, Halpern J, Bodison S, Gillison ML. Oral sexual behaviors associated with prevalent oral human papillomavirus infection. J Infect Dis. 2009:199:1263-9.

52. Frisch $M$, Hjalgrim $H$, Jaeger $A B$, Biggar RJ. Changing patterns of tonsillar squamous cell carcinoma in the United States. Cancer Causes Control. 2000; 11:489-95.

53. Chenevert J, Seethala RR, Barnes EL, Chiosea SI. Squamous cell carcinoma metastatic to neck from an unknown primary: the potential impact of modern pathologic evaluation on perceived incidence of human papillomavirus-positive oropharyngeal carcinoma prior to 1970. Laryngoscope. 2012;122:793-6.

54. Zur HH. Papillomaviruses and cancer: from basic studies to clinical application. Nat Rev Cancer. 2002;2:342-50.

55. Doorbar J, Quint W, Banks L, Bravo IG, Stoler M, Broker TR, et al. The biology and life-cycle of human papillomaviruses. Vaccine. 2012;30 Suppl 5:F55-70.

56. Huibregtse JM, Beaudenon SL. Mechanism of HPV E6 proteins in cellular transformation. Semin Cancer Biol. 1996;7:317-26.

57. Kubbutat $\mathrm{MH}$, Vousden $\mathrm{KH}$. Role of E6 and E7 oncoproteins in HPV-induced anogenital malignancies. Semin Virol. 1996;7:295-304.

58. Moody CA, Laimins LA. Human papillomavirus oncoproteins: pathways to transformation. Nat Rev Cancer. 2010;10:550-60.

59. Epstein MA, Achong BG, Barr YM. Virus particles in cultured lymphoblasts from Burkitt's lymphoma. Lancet. 1964;15:702-3. 
60. Ferry JA. Burkitt's lymphoma: clinicopathologic features and differential diagnosis. Oncologist. 2006;11:375-83.

61. Pattle SB, Farrell PJ. The role of Epstein-Barr virus in cancer. Expert Opin Biol Ther. 2006:6:1193-205.

62. van den Bosch CA. Is endemic Burkitt's lymphoma an alliance between three infections and a tumour promoter? Lancet Oncol. 2004;5:738-46.

63. Blum KA, Lozanski G, Byrd JC. Adult Burkitt leukemia and lymphoma. Blood. 2004;104:3009-20.

64. Cerilli LA, Holst VA, Brandwein MS, Stoler MH, Mills SE. Sinonasal undifferentiated carcinoma: immunohistochemical profile and lack of EBV association. Am J Surg Pathol. 2001;25:156-63.

65. Kuo T, Hsueh C. Lymphoepithelioma-like salivary gland carcinoma in Taiwan: a clinicopathological study of nine cases demonstrating a strong association with Epstein-Barr virus. Histopathology. 1997;31:75-82.

66. Tardío JC, Cristóbal E, Burgos F, Menárguez J. Absence of EBV genome in lymphoepithelioma-like carcinomas of the larynx. Histopathology. 1997;30:126-8.

67. Tsai CC, Chen CL, Hsu HC. Expression of Epstein-Barr virus in carcinomas of major salivary glands: a strong association with lymphoepithelioma-like carcinoma. Hum Pathol. 1996;27:258-62.

68. Weiss LM, Movahed LA, Butler AE, Swanson SA, Frierson Jr HF, Cooper PH, et al. Analysis of lymphoepithelioma and lymphoepithelioma-like carcinomas for Epstein-Barr viral genomes by in situ hybridization. Am J Surg Pathol. 1989;13:625-31.

69. Young LS, Dawson CW, Eliopoulos AG. The expression and function of Epstein-Barr virus encoded latent genes. Mol Path. 2000;53:238-47.

70. Leong IT, Fernandes BJ, Mock D. Epstein-Barr virus detection in nonHodgkin's lymphoma of the oral cavity: an immunocytochemical and in situ hybrid-ization study. Oral Surg Oral Med Oral Pathol Oral Radiol Endod. 2001:92:184-93.

71. Odds FC. Candida and candidosis: a review and bibliography. London, UK: Bailliere Tindale; 1988.

72. Bouza E, Muñoz P. Epidemiology of candidemia in intensive care units. Int J Antimicrob Agents. 2008;32 Suppl 2:S87-91.

73. Marol S, Yücesoy M. Molecular epidemiology of Candida species isolated from clinical specimens of intensive care unit patients. Mycoses. 2008:51:40-9.

74. Lamy M, Mojon P, Kalykakis G, Legrand R, Budtz-Jorgensen E. Oral status and nutrition in the institutionalized elderly. J Dent. 1999:27:443-8.

75. Scully C, El Kabir M, Samaranayake LP. Candida and oral candidosis: a review. Crit Rev Oral Biol Med. 1994:5:125-57.

76. Cawson RA, Binnie WH. Candida, leukoplakia and carcinoma: A possible relationship. In: Mackenzie I, Dabelsteen E, Squier CA, editors. Oral premalignancy. Proceedings of the first Dows symposium. lowa: University of lowa Press; 1980. p. 59-66.

77. Russell C, Jones JH. The histology of prolonged candidal infection of the rat's tongue. J Oral Pathol. 1975;4:330-9.

78. Krogh P, Hald B, Holmstrup P. Possible mycological etiology of oral mucosal cancer: Catalytic potential of infecting Candida albicans and other yeasts in production of N-nitrosobenzylmethylamine. Carcinogenesis. 1987:8:1543-8.

79. O'Grady JF, Reade PC. Candida albicans as a promoter of oral mucosal neoplasia. Carcinogenesis. 1992;13:783-6.

\section{Submit your next manuscript to BioMed Centra and we will help you at every step:}

- We accept pre-submission inquiries

- Our selector tool helps you to find the most relevant journal

- We provide round the clock customer support

- Convenient online submission

- Thorough peer review

- Inclusion in PubMed and all major indexing services

- Maximum visibility for your research

Submit your manuscript at www.biomedcentral.com/submit

) Biomed Central 